\title{
Punctuality of Patients and Physicians in an Outpatient Setting: Which Has a Greater Effect on Waiting Time?
}

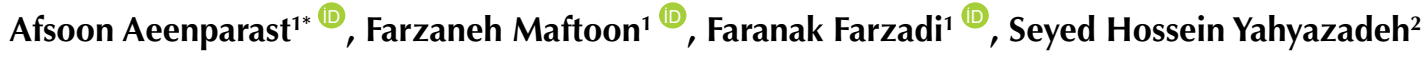 \\ ${ }^{1}$ Health Metrics Research Center, Iranian Institute for Health Sciences Research, ACECR, Tehran, Iran \\ ${ }^{2}$ Clinical Research Center, Milad Hospital, Tehran, Iran
}

\begin{abstract}
*Corresponding Author: Afsoon Aeenparast, Ph.D., Associate Professor, Health Metrics Research Center, Iranian Institute for Health Sciences Research, ACECR, Tehran, Iran. Tel: +98-9128191800, Email: aaeenparast@ihsr.ac.ir, aeenparast.af@gmail.com
\end{abstract}

Received February 25, 2021; Accepted July 17, 2021; Online Published September 12, 2021

\begin{abstract}
Background: Patients' waiting time for healthcare services is identified as one of the key measurements of an effective health system. This factor has an important role in patients' satisfaction as well. One factor that is related to the waiting time is patients' punctuality. Objectives: The objective of this study was assessing the effect of patients' and physicians' punctuality on outpatients' waiting time. Methods: This was a cross-sectional study. The study population was outpatients that were admitted in clinics of a general noneducational hospital. 3500 samples were selected from all clinics. The sampling method was stratified randomized method. Samples were included after taking the informed consent. Data gathered by check lists that recorded the patients work flow at the clinic and the time of arrival to and departure of each station.

Results: About $34 \%$ of patients had appointment that $98.5 \%$ of them were unpunctual. The correlation of patient unpunctuality (positive and negative) and their waiting time indicated that these variables had positive correlation $(P<0.001)$. Assessing the correlation of physicians' punctuality and patients' waiting time indicated that these variables also had positive correlation $(P<0.001)$.

Conclusion: Appointment systems are very useful in controlling patients waiting time. This study identified that patient's unpunctuality will increase patients waiting time. By the way negative punctuality will affect waiting time more that positive punctuality. Other important findings of this study were revealing the relation of physicians' unpunctuality and patients' waiting time. Punctuality of patients and providers are very important in the performance of appointment system in outpatient settings.

Keywords: Patient Appointments, Waiting Lists, Outpatients
\end{abstract}

\section{Background}

In recent decades, the health care organizations have observed major changes. Costs of the health sector is growing rapidly and the complexity of processes are increasing. These changes tend to increase the demand and supply of outpatient services and number of outpatients over the past decade. So outpatient settings and services has been more concerned. ${ }^{1-3}$ Today there are general attention to increase patient access, improve patient throughput, enhance patient satisfaction and provide high quality care in outpatient settings. ${ }^{4}$

A considerable amount of patients waiting time in the clinics is related to the services of physicians and other health professionals. Waiting time refers to the time a patient waits in the clinic until being visited by one of the medical staff. Studies indicated that the health consumers' satisfaction of care in outpatient settings is strongly and positively related to the quality of the waiting experience. ${ }^{5}$
World Health Organization (WHO) defined patient waiting time for healthcare services, as one of the key measurements of a responsive health system. This factor has an important role in patients' satisfaction as well. ${ }^{6}$ ${ }^{8}$ Extra waiting time have no value added on the outputs of the system, because during this period, resources are idle and patients' medical condition do not change in this period. ${ }^{8,9}$

Barlow argues that long waiting time is a lose-lose strategy because not only patients lose their valuable time; but also hospitals lose their patients and staff experience tension and stress. ${ }^{8,10}$ The studies indicated that waiting time is a systematic problem that not only impact on patients' satisfaction but also have negative effects on working processes of outpatient settings. ${ }^{11}$ Waiting time may be created by different processes in the service delivery system. For better managing the waiting time the processes that lead to waiting time should be identified.

Copyright (C) 2021 The Author(s). This is an open-access article distributed under the terms of the Creative Commons Attribution License (http:// creativecommons.org/licenses/by/4.0), which permits unrestricted use, distribution, and reproduction in any medium, provided the original work is properly cited. 
The processes and factors that create waiting time, may vary from one setting to another but most of them are similar through different settings.

One factor related to waiting time and the other metrics of clinic performance is patients' punctuality. Unpunctuality is defined as the differences between appointment time and arrival time. ${ }^{12}$ Patients who arrive earlier or later than their appointment time, may complicate appointment policies and schedules. In turn patients who arrive on time for their outpatient appointments are very helpful in smoothing clinic performance. When more patients are punctual, clinics run smoothly and the likelihood of clinic overtime decreased. ${ }^{13}$ There are two kinds of unpunctuality in references: negative and positive. Negative unpunctuality reflects early arrival and positive unpunctuality reflects late arrival. ${ }^{12}$

\section{Objectives}

In this study the effect of patient punctuality on waiting time was assessed. In addition, the effects of timely attendance of physician and patient punctuality on waiting time also were compared.

\section{Methods}

This was a cross-sectional study that was done in 2013. The study population was that were admitted outpatients in clinics of a general non-educational hospital in Tehran, Iran. The large variety of outpatient services is provided in this hospital. Patients are admitted in hospital clinics in both forms: scheduled and walk in. 3500 samples were selected from all 14 specialty clinics consist of: internal medicine, general surgery, obstetrics and gynaecology, cardiology, infectious disease, orthopaedic, urology, ear nose and throat, dermatology, ophthalmology, psychology, neurology, neurosurgery and anaesthesiology. Sample size for each clinic was considered at list 250 samples by considering confidence interval 95\%, Power level 80\%, standard deviation 5.12 minutes and tolerated margin of error 1 minute. ${ }^{14}$ The sampling method was stratified randomized method.

Before data gathering, the aim and process of the study were explained to the patients and only patients who were pleased to participate in the study were included in the study so the inclusion criteria for samples were admission to hospital clinics, visiting by physicians and being content to participating in the study. We excluded patients that could not admit or receive outpatient visit or patients who did not consent to participate in the study. Data gathered by check lists that was made by considering the aim of the study and outpatient workflow at the setting. The check lists recorded the patients work flow at the clinic and the time of arrival to and departure of each station. The content validity of check lists was proved by experts and hospital authorized. Data gathering phase was done by 5 trained questioners that were familiar with the hospital and its' work flow.

SPSS 19 was used for data analysis. Different descriptive and analytical tests were used by considering the distribution of data including mean, median, standard deviation, range, paired sample $t$ test, one way analysis of variance (ANOVA), and correlation. The level of significance was considered 0.05 .

\section{Results}

The descriptive analysis of demographic characteristics of care receivers indicated that the mean age of the studied outpatients were 43.2 years $(\mathrm{SD}=19.9)$. Most of the sample were female $(63.4 \%)$, were married $(78.6 \%)$, have diploma (31.7 \%) and live in Tehran (72.5\%). Most of the respondents were household (45.5\%) and retired (15.5\%) (Table 1).

The samples were waited about 57.7 minutes $(S D=54.9)$ to visit the doctor. Other descriptive statistics indicated that the median of this variable was 65 minutes (range= 0-297 minutes)

Most of patients came to the clinic without appointment and about $34 \%$ of them had appointment. Most of scheduled patients indicated that their attendance time was set at the time of taking appointment. The defined time of attendance was asked from patients. The admission status of studied samples is presented in Table 2 .

More investigation indicated that just 1.5 present of scheduled patients that know their entrance time, were completely punctual. The others come sooner or later (Table 3).

Analysis shows negative unpunctual patients in average 41.1 minutes come soon and positive punctual patients in average 45.0 minutes come late.

Table 1. The Demographic Characteristics of Respondents $(n=3500)$

\begin{tabular}{llcc}
\hline Variable & & Frequency & Percent \\
\hline \multirow{3}{*}{ Gender } & Female & 2219 & 63.4 \\
& Male & 1281 & 36.6 \\
\multirow{4}{*}{ Marriage statues } & Single & 532 & 15.2 \\
& Married & 2751 & 78.6 \\
& Other & 217 & 6.2 \\
\multirow{3}{*}{ Education } & Illiterate & 644 & 18.4 \\
& Elementary & 780 & 22.3 \\
& High school & 536 & 15.3 \\
Address & Diploma & 1110 & 31.8 \\
& University & 423 & 12.2 \\
& Tehran city & 2537 & 45.3 \\
& Tehran province & 543 & 15.5 \\
& Other provinces & 212 & 6.1 \\
& Household & 1586 & 45.3 \\
& Retired & 543 & 15.5 \\
& Student & 212 & 6.1 \\
& Employee & 324 & 9.3 \\
& Self-employment & 461 & 13.2 \\
& Unemployed & 234 & 6.7 \\
& Others & 140 & 4.0 \\
\hline
\end{tabular}


Table 2. The Admission Status of Studied Outpatients $(n=3500)$

\begin{tabular}{|c|c|c|c|}
\hline Variable & & Frequency & Percent \\
\hline \multirow{2}{*}{ Type of admission } & Walk in & 2296 & 65.5 \\
\hline & Scheduled & 1203 & 34.5 \\
\hline \multirow{4}{*}{$\begin{array}{l}\text { Define the time } \\
\text { of attendance } \\
\text { (in scheduled } \\
\text { admission) }\end{array}$} & Yes & 933 & 77.6 \\
\hline & No & 45 & 3.7 \\
\hline & Don't know & 60 & 5.0 \\
\hline & Without answer & 165 & 13.7 \\
\hline
\end{tabular}

Table 3. The situation of punctuality of patients referred to the studied outpatient setting $(n=933)$

\begin{tabular}{lcc}
\hline Patients Punctuality & Frequency & Percent \\
\hline Punctual & 13 & 1.5 \\
Negative unpunctual (come soon) & 331 & 35.5 \\
Positive unpunctual (come late) & 583 & 62.6 \\
missing & 3 & 0.4 \\
\hline
\end{tabular}

The correlation of patient unpunctuality and their waiting time indicated that these variables had positive correlation (Table 4).

In this study also the punctuality of physicians was measured. About $7.1 \%$ of physicians start their work sooner than 8:00 AM, 10.3\% start their work on time and $82.6 \%$ start their work later than 8:00 AM. The correlation of physician unpunctuality and patients' waiting time indicated that these variables had positive correlation (Table 4).

\section{Discussion}

Waiting time is an important factor that should be considered in outpatient settings. Waiting time cannot be eliminated completely, but it can be managed and reduced. . $^{3,15}$

There are many factors affecting the waiting time of outpatients. In order to reduce waiting time these factors should be controlled. Appointment systems are very useful in controlling patients waiting time. Waiting time can be reduced by controlling patient arrival, flow in the system and by Setting the Clinic Schedule. ${ }^{16}$

There are certain factors that disrupt the normal order of the appointment system and affect the system's performance. These factors include the punctualities of patients and care providers. ${ }^{12,17,18}$

In This study, it was found that the unpunctuality of patients will increase their waiting time. Another study also revealed that reducing unpunctuality of patients decreases delays. In other words, when unpunctuality was reduced, patient waiting times after the appointment time was reduced too. ${ }^{12}$

By the way it appears that punctuality has more benefits. Reducing patients' unpunctuality significantly decreases the likelihood of clinic overtime. For instance a study showed that increasing patients' punctuality improved the likelihood of completing the morning schedule by 12:00 from 38 to $51 \% .^{12}$
Table 4. Correlation of the Amount of Patient and Physician Unpunctuality and Their Waiting Time

\begin{tabular}{llcc}
\hline Variable & & $\begin{array}{c}\text { Spearman } \\
\text { Correlation }\end{array}$ & P Value \\
\hline Patient unpunctuality & Negative & +0.45 & $<0.001$ \\
& Positive & +0.23 & $<0.001$ \\
Physician unpunctuality & positive & +0.37 & $<0.001$ \\
\hline
\end{tabular}

The results of the study showed that negative punctuality of patients will have a more serious effect on waiting time compared to positive punctuality. It means that patients who arrive earlier than their appointment time have to wait more compared to patients who arrive late.

Patients should be informed that unpunctuality is an inappropriate behavior that negatively affects the performance of the service providing system. They should know that this is true for both positive and negative unpunctuality. However, sometimes patients do not consider negative punctuality as a negative behavior. Several researchers have verified that customers have different views about waiting before the promised service time and waiting after the promised service time. Many service providers recommend that their patients should not arrive before their appointment time and mentioned that this behavior will increase their waiting time. ${ }^{19}$

Other important findings of this study have revealed the relationship between physicians' lateness on patients' waiting time. It appears that the attendance of physicians is very important in on time start of clinic. Comparing the effect of physicians' and patients waiting time revealed that physicians' unpunctuality has less effect on patients' waiting times compared to the patients' negative unpunctuality and more than the patients' positive unpunctuality. Although the result of statistical analysis has been confirmed, it is believed in a system, the physicians' unpunctuality should be managed prior to the patients' unpunctuality. Because the Physicians' unpunctuality may not only interrupt the order of scheduled work directly, but it can also affect patients' behavior and punctuality and may interrupt scheduled work indirectly. It appears that Patients will trust and obey the rules of a punctual system more compared to an unpunctual system. It means that launching the system on time will encourage patients to follow the timetable and be more punctual. ${ }^{20}$

\section{Conclusion}

In closing, patients' arrival and punctuality are very important factors for smooth flow at the system and waiting time. However, it should be considered that improving the disciplines of the service provider system including providers' punctuality is in first priority.

\section{Authors' Contributions}

AA, FM and FF contributed to the study design, literature review, article writing. SHY contributed to data gathering. The authors read and approved the final version of the manuscript. 


\section{Conflict of Interest Disclosures}

The authors declare that they have no conflicts of interest.

\section{Ethical Approval}

explained to the patients an Before data gathering, the aim and process of the study were $\mathrm{d}$ only patients who were pleased to participate in the study were included in the study. Patients who withdraw of the study did not take any negative point for receiving their services.

\section{Acknowledgements}

This article is based on "patient's flow analysis and assessing the waiting time in hospital clinics" research project. This study is funded by contract (10100128) on $14^{\text {th }}$ Nov. 2012 and planed and implemented by Iranian Institute for Health Sciences Research (IHSR). The authors would like to thank everybody that contributed in this study.

\section{References}

1. Viberg N, Forsberg BC, Borowitz M, Molin R. International comparisons of waiting times in health care--limitations and prospects. Health Policy. 2013;112(1-2):53-61. doi:10.1016/j. healthpol.2013.06.013

2. Aeenparast A, Tabibi SJ, Shahanaghi K, Aryanejhad MB. Reducing outpatient waiting time: a simulation modeling approach. Iran Red Crescent Med J. 2013;15(9):865-869. doi:10.5812/ircmj.7908

3. Mohebbifar R, Hasanpoor E, Mohseni M, Sokhanvar M, Khosravizadeh O, Mousavi Isfahani H. Outpatient waiting time in health services and teaching hospitals: a case study in Iran. Glob J Health Sci. 2013;6(1):172-180. doi:10.5539/ gjhs.v6n1p172

4. Cheong S, Bitmead RR, Fontanesi J. Modeling scheduled patient punctuality in an infusion center. Lecture Notes in Management Science. 2013;5:46-56.

5. Oche M, Adamu H. Determinants of patient waiting time in the general outpatient department of a tertiary health institution in north Western Nigeria. Ann Med Health Sci Res. 2013;3(4):588-592. doi:10.4103/2141-9248.122123

6. Sun J, Lin Q, Zhao P, et al. Reducing waiting time and raising outpatient satisfaction in a Chinese public tertiary general hospital-an interrupted time series study. BMC Public Health. 2017;17(1):668. doi:10.1186/s12889-017-4667-z

7. Westeneng JB. Outpatient Appointment Scheduling: An Evaluation of Alternative Appointment Systems to Reduce Waiting Times and Underutilization in an ENT Outpatient
Clinic [thesis]. University of Twente; 2007.

8. Pillay DI, Ghazali RJ, Abd Manaf NH, et al. Hospital waiting time: the forgotten premise of healthcare service delivery? Int J Health Care Qual Assur. 2011;24(7):506-522. doi:10.1108/09526861111160553

9. Kujala J, Lillrank P, Kronström V, Peltokorpi A. Time-based management of patient processes. J Health Organ Manag. 2006;20(6):512-524. doi:10.1108/14777260610702262

10. Barlow GL. Auditing hospital queuing. Manag Audit J. 2002;17(7):397-403. doi:10.1108/02686900210437507

11. Brandenburg L, Gabow P, Steele G, Toussaint J, Tyson BJ. Innovation and Best Practices in Health Care Scheduling. Washington, DC: National Academy of Medicine; 2015. doi:10.31478/201502g

12. Williams KA, Chambers CG, Dada M, McLeod JC, Ulatowski JA. Patient punctuality and clinic performance: observations from an academic-based private practice pain centre: a prospective quality improvement study. BMJ Open. 2014;4(5):e004679. doi:10.1136/bmjopen-2013-004679

13. Klassen KJ, Yoogalingam R. Strategies for appointment policy design with patient unpunctuality. Decis Sci. 2014;45(5):881-911. doi:10.1111/deci.12091

14. Aeenparast A, Tabibi SJ, Shahanaghi K, Aryanejhad MB. Estimating outpatient waiting time: a simulation approach. Payesh. 2009;8(4):327-333. [Persian].

15. Creemers S, Lambrecht M, Vandaele N. Queueing models in healthcare. Tijdschrift voor Economie en Management. 2007;52(3):471-497.

16. Harper PR, Gamlin HM. Reduced outpatient waiting times with improved appointment scheduling: a simulation modelling approach. OR Spectrum. 2003;25(2):207-222. doi:10.1007/s00291-003-0122-x

17. Bhattacharjee P. Modelling and Analysis of Hospital Appointment Scheduling Systems [thesis]. Kharagpur: IIT; 2016.

18. Aliyu AI, Sulaiman TA, Yusuf A. Modeling and simulation analysis of health care appointment system using ARENA. Int J Sci Appl Inf Technol. 2015;4(1):1-7.

19. Maister DH. The Psychology of Waiting Lines. Boston, MA: Harvard Business School; 1984.

20. Edward A, Osei-Bonsu K, Branchini C, Yarghal TS, Arwal $\mathrm{SH}$, Naeem AJ. Enhancing governance and health system accountability for people centered healthcare: an exploratory study of community scorecards in Afghanistan. BMC Health Serv Res. 2015;15:299. doi:10.1186/s12913-015-0946-5 